\title{
Spin-crossover in Chromium-catalyzed Ethylene Trimerization: Density Functional Theory Study
}

\author{
Md. Anwar Hossain, Hoon Sik Kim, K. N. Houk, ${ }^{\dagger}$ and Minserk Cheong ${ }^{*}$ \\ Department of Chemistry and Research Institute of Basic Sciences, Kyung Hee University, Seoul 130-701, Korea \\ *E-mail: mcheong@khu.ac.kr \\ ${ }^{\dagger}$ Department of Chemistry and Biochemistry, University of California, Los Angeles, California 90095-1569, United States \\ Received March 7, 2014, Accepted May 7, 2014
}

Key Words : Chromium catalyst, Spin-crossover, Ethylene trimerization, Density functional theory

Industrially important linear alpha-olefins are commonly produced by oligomerization of ethylene or by FischerTropsch synthesis followed by purification. Biggest challenge for the linear alpha olefin industry is a Schultz-Flory distribution of products made by most of the processes. ${ }^{1}$ With 8-10 products being made at the same time, with most of them sold into different markets with different dynamics, it is difficult to balance the supply and the demand for all or even most products.

Recent findings of selective ethylene trimerization catalysts (mostly based on chromium, ${ }^{2}$ even though other titanium, ${ }^{3}$ nickel, ${ }^{4}$ and tantalum ${ }^{5}$ are also known) prompted many scientists to study the reaction mechanism to figure out the high selectivity towards trimerization of ethylene with these catalysts. Experimental and theoretical investigations led to widely accepted redox reaction/ring-expansion mechanism. ${ }^{2,6}$

Chromium complexes are the catalyst precursors that are most commonly used since these complexes give most selective and active transformations. For example, a catalyst system comprising $\mathrm{Ar}_{2} \mathrm{PN}(\mathrm{Me}) \mathrm{PAr}_{2}(\mathrm{Ar}=2$-methoxyphenyl, abbreviated as $\mathrm{PNP}$ ) and $\left[\mathrm{CrCl}_{3}(\mathrm{THF})_{3}\right]$, activated with methyl aluminoxane (MAO) yields 99.9 wt \% 1-hexene in $\mathrm{C}_{6}$ fraction and $89.9 \mathrm{wt} \%$ 1-hexene overall with activity of

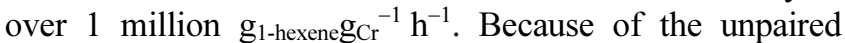
electrons in the valence shell of the chromium, it is difficult to examine the characteristics of the paramagnetic $\mathrm{Cr}$ catalysts using usual NMR method. Therefore, X-ray crystallography is the only acceptable method experimentally. The need for open shell calculation also impeded theoreticians from studying the reactions computationally due to SCF convergence problems and long computing time.

The effect of ligand in the electron paring energy of $\mathrm{Cr}$ (III) complexes was studied by Cacelli et al., ${ }^{7}$ quartet being the ground state. Also the study by Blom et al. ${ }^{8}$ on the cyclopentadienyl chromium complexes showed quartet is always the most stable state. However, the multiplicity of $\mathrm{Cr}$ catalyst changes during the reaction because of the oxidation state change. Until now, the change in the multiplicity in the chromium-catalyzed ethylene trimerization has not been studied in detail. In order to study this kind of spin crossing phenomenon during the catalytic cycle, it is imperative to examine all possible spin states of important intermediates.
In this paper, we studied the entire catalytic cycle for chromium-catalyzed ethylene trimerization focusing on the spin-crossover using density functional theory (DFT) method.

$$
3 \mathrm{C}_{2} \mathrm{H}_{4} \rightarrow \mathrm{C}_{6} \mathrm{H}_{12}
$$

DFT calculation was performed using Gaussian 03 program. ${ }^{9}$ Among various ligands, we chose PNP-type ligand as a model since it is the most active and selective ligand. Specifically, we used $\mathrm{H}_{2} \mathrm{PNHPH}_{2}$ since it is the simplest form to resemble our catalytic system. The anion fragment is proposed to consist of Cl-MAO unit, which remains elusive because of complexity of its structure, and omitted in the discussion for simplicity. The geometry optimizations and thermodynamic corrections were performed with unrestricted hybrid Becke 3-Lee-Yang-Parr (UB3LYP) exchangecorrelation functional with the $6-31+\mathrm{G}^{*}$ basis sets for $\mathrm{C}, \mathrm{H}$, $\mathrm{N}$, and $\mathrm{P}$ and LanL2DZ(ECP) basis sets for Cr. All stationary points were verified as minima or transition states by full calculation of the Hessian and a harmonic frequency analysis. The calculated number of imaginary frequency (NImag) is 0 for energy minimum structures and 1 for transition states. The magnitude of imaginary frequency and corresponding eigenvectors were analyzed for all transition states to verify involvement of require atoms. Intrinsic reaction coordinate $(\mathrm{IRC})^{10}$ calculation were used to confirm the connectivity between transition structures and minima.

The proposed mechanism for ethylene oligomerization with a PNP-based system is illustrated in Figure 1. Catalyst initiation is proposed to involve reduction of $\mathrm{Cr}(\mathrm{III})$ to $\mathrm{Cr}(\mathrm{I})$ by MAO, ligand exchange, and coordination of two ethylene molecules to yield species 1 as the first active intermediate in the catalytic cycle. Metallacycle formation from 1 involves oxidative addition of two ethylene fragments to yield a fivemembered $\mathrm{Cr}$ (III) metallacycle, 2. At this stage, 1-butene can be liberated by reductive eliminative intramolecular $\beta$ hydrogen migration to the $\delta$-carbon and regeneration of the active catalytic $\mathrm{Cr}(\mathrm{I})$ species, 1 , upon coordination of two ethylene molecules. On the other hand, the energetically more favorable coordination of a third ethylene molecule can be followed to yield 3 if 1-butene generation is energetically demanding. Subsequent metallacycle growth results from insertion of the third ethylene molecule into the five- 


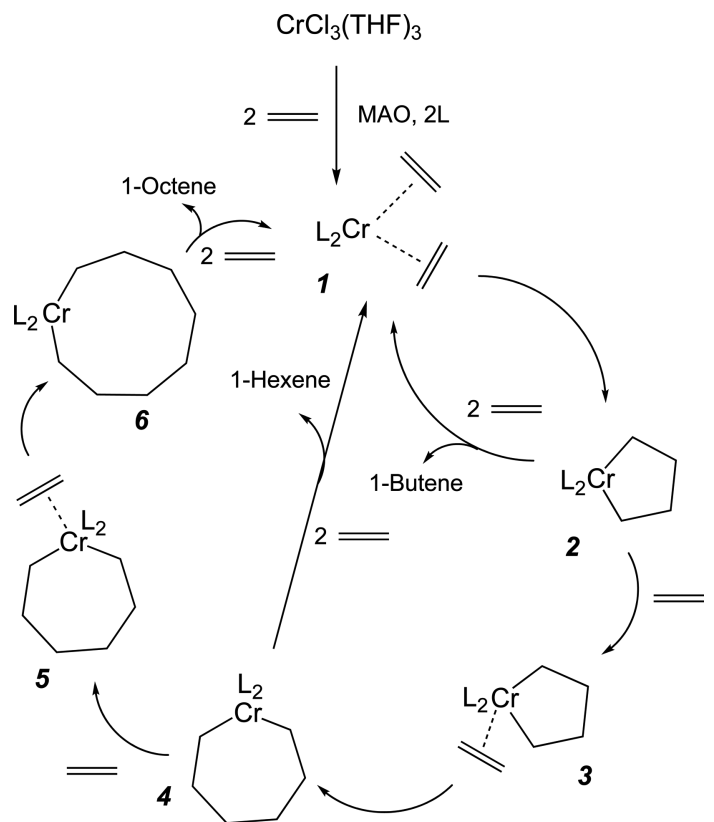

Figure 1. Catalytic cycle for ethylene oligomerization with a PNP-based chromium catalyst system. $\mathrm{L}_{2}=\mathrm{H}_{2} \mathrm{PNHPH}_{2}$.

membered metallacycle ring to yield the seven-membered metallacycle species 4 . At this time, 1-hexene can be liberated via reductive eliminative intramolecular $\beta$-hydrogen migration to the $\zeta$-carbon and regeneration of the active catalytic $\mathrm{Cr}(\mathrm{I})$ species, $\mathbf{1}$, upon coordination of two ethylene molecules. Depending on the energetics of coordinating another ethylene molecule, further expansion of metallacyclic ring can occur.

The first possibility of spin-crossover was tested for 1butene formation. The reaction intermediates and transition states involved in the first catalytic cycle for the formation of 1-butene are shown in Figure 2. Two spin states for $\mathrm{Cr}(\mathrm{I})$ and $\mathrm{Cr}$ (III) complexes (quartet and sextet) were considered. As shown in Figure 2, the sextet state is more stable than the quartet state for $\mathrm{Cr}(\mathrm{I})$ and the reverse is true for $\mathrm{Cr}(\mathrm{III})$. The structure of starting intermediate $\boldsymbol{l}$ is tetrahedral for the more stable sextet state and square planar for the less stable quartet state. In case of five-membered $\mathrm{Cr}$ (III) metallacycle, 2 , the structure is square planar for the less stable sextet state and tetrahedral for the more stable quartet state. Therefore, the spin state crossing occurs at the transition state (TS(1-2)) where quartet TS is more stable than sextet TS. In other words, it starts as a sextet tetrahedral structure and changes to a quartet square planar structure at the TS(1-2) of the oxidative coupling step and changes back to a quartet tetrahedral structure of the metallacycle. Because of the strain of the five-membered metallacycle, a two-step process involving $\beta$-hydrogen abstraction $\left(\mathrm{TS}_{\mathrm{a}}(2-7)\right)$ and reductive elimination $\left(\mathrm{TS}_{\mathrm{b}}(2-7)\right)$ ensues to produce 1-butene via 3-butenylhydrido intermediate $($ Int 1$)$. Here once again, spin state changes from quartet $\mathrm{Cr}(\mathrm{III}) \mathrm{TS}$ to sextet trigonal planar $\mathrm{Cr}(\mathrm{I})$ product (7).

Whether to proceed to make a larger metallacycle 4 from 2

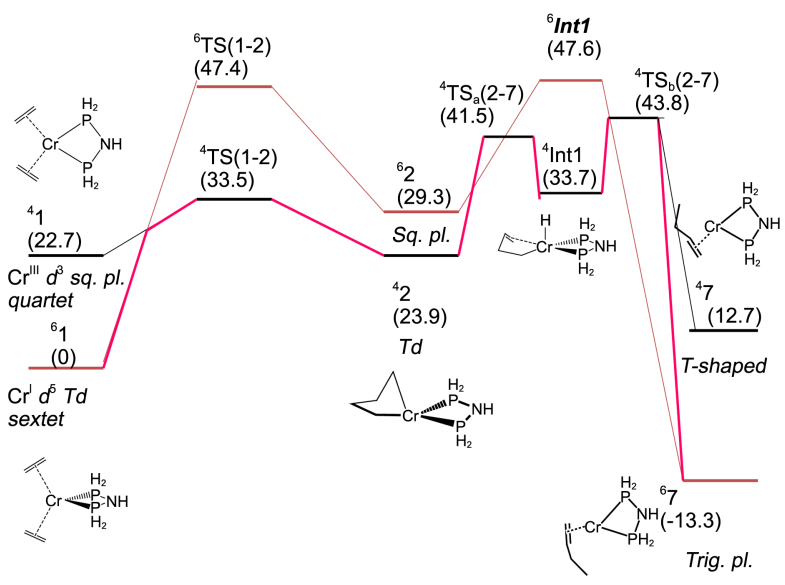

Figure 2. Energy profile calculated for ethylene dimerization with a PNP-based chromium catalyst system showing spin-crossover. The relative Gibbs free energies are given in $\mathrm{kcal} / \mathrm{mol}$ in parenthesis.

by insertion of another ethylene molecule or to produce 1butene depends on the relative energetics. The free energy of activation for the formation of metallacycloheptane 4 is 10.5 $\mathrm{kcal} / \mathrm{mol}$ (Figure S1) whereas the conversion of metallacyclopentane into 1-butene occurs with an activation free energy of $19.9 \mathrm{kcal} / \mathrm{mol}$ as shown in Figure 2. This preference of ethylene insertion contributes to the eventual generation of 1-hexene instead of 1-butene.

To produce 1-hexene from 3, two different routes are possible, one via ethylene insertion followed by intramolecular $\beta$-hydrogen migration and the other via alkyl transfer followed by reductive elimination. The former route is calculated to be preferable to the latter route by $21.5 \mathrm{kcal} /$ mol as shown in Figure S1.

With metallacycloheptane 4 , a concerted process called an agostic-assisted hydride shift occurs instead of a two-step process. ${ }^{6 c}$ As shown in Figure 3, this concerted process is with an activation free energy of only $18.1 \mathrm{kcal} / \mathrm{mol}$ compared with a stepwise process of $23.3 \mathrm{kcal} / \mathrm{mol}$. As the case for 1-

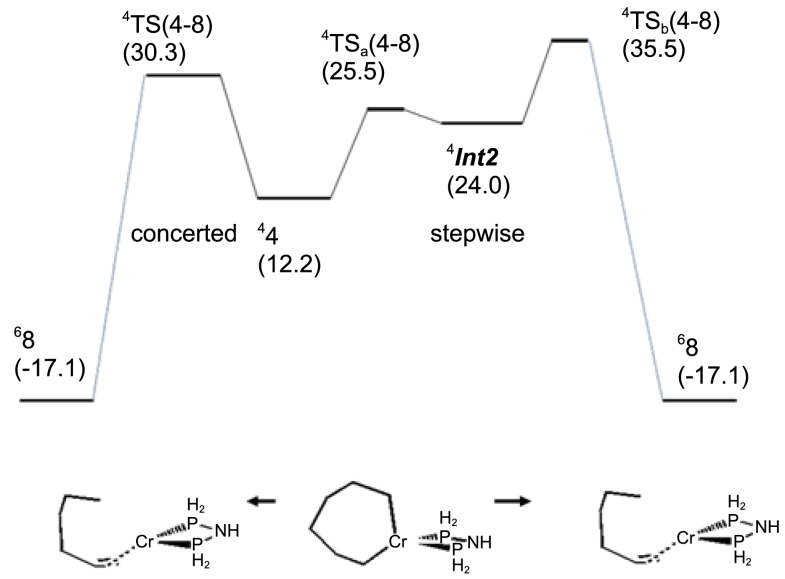

Figure 3. Energy profile calculated for the production of 1-hexene from the seven-membered metallacycle species via two different routes showing spin-crossover. The relative Gibbs free energies are given in $\mathrm{kcal} / \mathrm{mol}$ in parenthesis. 


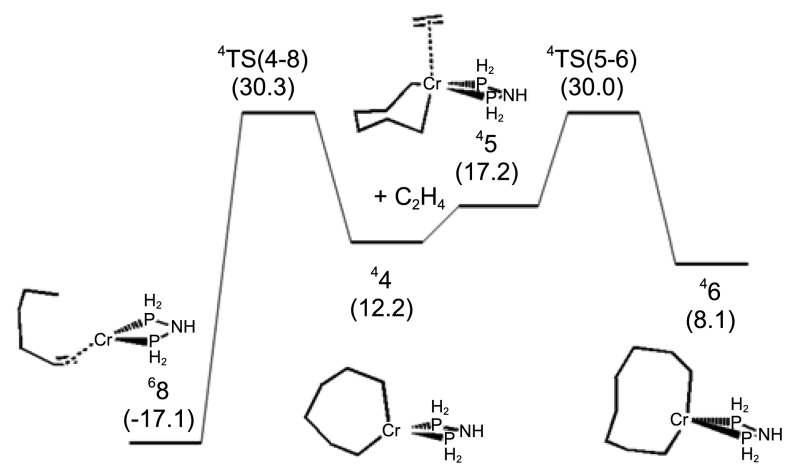

Figure 4. Calculated energy profile comparing the production of 1-hexene with the formation of metallacyclononane. The relative Gibbs free energies are given in $\mathrm{kcal} / \mathrm{mol}$ in parenthesis.

butene, spin state crossing occurs at the transition state as shown in Figure 3 and the reaction is highly exergonic with a free energy of $-17.1 \mathrm{kcal} / \mathrm{mol}$.

Whether to expand ring size further to nine also depends on the relative energetics. The free energy of activation for the formation of metallacyclononane 6 is $17.8 \mathrm{kcal} / \mathrm{mol}$ and the conversion of metallacycloheptane into 1-hexene occurs with an activation free energy of $18.1 \mathrm{kcal} / \mathrm{mol}$ as shown in Figure 4. Since both processes are similar in energetics, coproduction of 1-hexene and 1-octene occurs with this type of simple Cr-PNP catalysts, which is consistent with experimental results. Therefore, to produce 1 -hexene selectively a delicate control of the ligand structure is needed.

Production of 1-octene via agnostic-assisted hydride transfer occurs with a spin state change from quartet $\mathrm{Cr}$ (III) TS to sextet trigonal planar $\mathrm{Cr}(\mathrm{I})$ product. Further expansion of ring size is not favored to 1-octene production by $2.8 \mathrm{kcal} /$ mol. So metallacyclic ring expansion stops at nine.

As a whole, the rate-determining step is oxidative coupling step $\left({ }^{4} \mathrm{TS}(1-2)\right)$ to make a metallacyclopentane which is consistent with the kinetics of the reaction showing secondorder dependence of the rate on the concentration of ethylene.

In conclusion, the density functional study on the mechanism of Cr-PNP catalyzed ethylene trimerization including spin state change has shown the co-production of 1-hexene and 1-octene.

Acknowledgments. This work was supported by a grant from the Kyung Hee University in 2010 (KHU-20100663).

Supporting Information Available. Figure S1 and a table giving Cartesian coordinates of all optimized structures of reaction intermediates and transition states involved in the reaction pathway.

\section{References}

1. (a) Skupinska, J. Chem. Rev. 1991, 91, 613. (b) Ruther, T.; Braussaud, N.; Cavell, K. J. Organometallics 2001, 20, 1247. (c) Svejda, S. A.; Brookhart, M. Organometallics 1999, 18, 65. (d) Jones, D.; Cavell, K. J.; Keim, W. J. Mol. Catal. A 1999, 138, 37. (e) Small, B. L.; Brookhart, M. J. Am. Chem. Soc. 1998, 120, 7143. (f) Killian, C. M.; Johnson, L. K.; Brookhart, M. Organometallics 1997, 16, 2005. (g) Peuckert, M.; Keim, W. Organometallics 1983, 2, 594.

2. (a) Manyik, R. M.; Walker, W. E.; Wilson, T. P. Union Carbide Corporation, US Patent 3300458, 1967. (b) Briggs, J. R. Chem. Commun. 1989, 674. (c) Emrich, R.; Heinemann, O.; Jolly, P. W.; Krueger, C.; Verhovnik, G. P. J. Organometallics 1997, 16, 1511. (d) Manyik, R. M.; Walker, W. E.; Wilson, T. P. J. Catal. 1977, 47, 197. (e) Yang, Y.; Kim, H.; Lee, J.; Paik, H.; Jang, H. G. Appl. Catal. A 2000, 193, 29. (f) Wasserscheid, P.; Grimm, S.; Köhn, R.; Haufe, M. Adv. Synth. Catal. 2001, 343, 814. (g) Carter, A.; Cohen, S. A.; Cooley, N. A.; Murphy, A.; Scutt, J.; Wass, D. F. Chem. Commun. 2002, 858. (h) Monoi, T.; Sasaki, Y. J. Mol. Catal. A: Chem. 2002, 187, 135. (i) McGuinness, D. S.; Wasserscheid, P.; Keim, W.; Hu, C.; Englert, U.; Dixon, J. T.; Grove, C. Chem. Commun. 2003, 334. (j) McGuinness, D. S.; Wasserscheid, P.; Keim, W.; Morgan, D.; Dixon, J. T.; Bollmann, A.; Maumela, H.; Hess, F.; Englert, U. J. Am. Chem. Soc. 2003 125, 5272. (k) Morgan, D. H.; Schwikkard, S. L.; Dixon, J. T.; Nair, J. J.; Hunter, R. Adv. Synth. Catal. 2003, 345, 939. (1) Commereuc, D.; Drochon, S.; Saussine, L. (Institut Francais du Petrole) US Patent 6031145, 2000. (m) Wu, F.-J. (Amoco Corp.) US Patent 5811618, 1998. (n) Aoyama, T.; Mimura, H.; Yamamoto, T.; Oguri, M.; Koie, Y. (Tosoh Corp.) JP Patent 09176229, 1997. (o) Jolly, P. W. Acc. Chem. Res. 1996, 29, 544.

3. (a) Deckers, P. J. W.; Hessen, B.; Teuben, J. H. Angew. Chem., Int. Ed. 2001, 40, 2516. (b) Deckers, P. J. W.; Hessen, B.; Teuben, J. H. Organometallics 2002, 21, 5122. (c) Pellechia, C.; Pappalardo, D.; Oliva, L.; Mazzeo, M.; Gruter, G.-J. Macromolecules 2000, 33, 2807.

4. Andes, C.; Harkins, S. B.; Murtuza, S.; Oyler, K.; Sen, A. J. Am. Chem. Soc. 2001, 123, 7423.

5. Santi, R.; Romano, A. M.; Grande, M.; Sommazzi, A.; Masi, F.; Proto, A. (ENICHEM S.P.A.) WO 0168572, 2001.

6. (a) McDermott, J. X.; White, J. F.; Whitesides, G. M. J. Am. Chem. Soc. 1976, 98, 6521. (b) Köhn, R. D.; Haufe, M.; KociokKöhn, G.; Grimm, S.; Wasserscheid, P.; Keim, W. Angew. Chem. Int. Ed. 2000, 39, 4337; (c) Yu, Z.; Houk, K. N. Angew. Chem. Int. Ed. 2003, 42, 808. (d) McGuinness, D. S.; Wasserscheid, P.; Morgan, D. H.; Dixon, J. T. Organometallics 2005, 24, 552. (e) Bluhm, M. E.; Walter, O.; Döring, M. J. Organomet. Chem. 2005, 690, 713. (f) Agapie, T.; Labinger, J. A.; Brecaw, J. E. J. Am. Chem. Soc. 2007, 129, 14281. (g) McGuinness, D. S.; Suttil, J. A. Gardiner, M. G.; Davies, N. W. Organometallics 2008, 27, 4238. (h) Zhang, J.; Braunstein, P.; Hor, T. S. A. Organometallics 2008, 27, 4277. (i) Peitz, S.; Peulecke, N.; Aluri, B. R.; Hansen, S.; Müller, B. H.; Spannenberg, A.; Rosenthal, U.; Al-Hazmi, M. H. Mosa, F. M.; Wöhl, A.; Müller, W. Eur. J. Inorg. Chem. 2010, 1167. (j) Hey, T. W.; Wass, D. F. Organometallics 2010, 29, 3676. (k) Köhn, R. D.; Haufe, M.; Mihan, S.; Lilge, D. Chem. Commun. 2000, 1927. (1) Bowen, L. E.; Haddow, M. F.; Orpen, A. G.; Wass, D. Dalton Trans. 2007, 1160. (m) Rucklidge, A. J.; McGuinness, D. S.; Tooze, R. P.; Slawin, A. M. Z.; Pelletier, J. D. A.; Hanton, M. J.; Webb, P. B. Organometallics 2007, 26, 2782. (n) Jabri, A.; Mason, C. B.; Sim, Y.; Gambarotta, S.; Burchell, T. J.; Duchateau, R. Angew. Chem. Int. Ed. 2008, 47, 9717. (o) Dulai, A.; de Bod, H.; Hanton, M. J.; Smith, D. M.; Downing, S.; Mansell, S. M.; Wass, D. F. Organometallics 2009, 28, 4613. (p) Licciulli, S.; Albahily, K.; Fomitcheva, V.; Korobkov, I.; Gambarotta, S.; Duchateau, R. Angew. Chem. Int. Ed. 2011, 50, 2346. (q) Skobelev, I. Y.; Panchenko, V. N.; Lyakin, O. Y.; Bryliakov, K. P. V.; Zakharov, A.; Talsi, E. P. Organometallics 2010, 29, 2943. (r) Budzelaar, P. H. M. Can. J. Chem. 2009, 87, 832. (s) Albahily, K.; Shaikh, Y.; Sebastiao, E.; Gambarotta, S.; Korobkov, I.; Gorelsky, S. I. J. Am. Chem. Soc. 2011, 133, 6388.

7. (a) Cacelli, I.; Keogh, D. W.; Poli, R.; Rizzo, A. New J. Chem. 1997, 21, 133. (b) Cacelli, I.; Keogh, D. W.; Poli, R.; Rizzo, A. J. 
Phys. Chem. A 1997, 101, 9801.

8. Blom, B.; Klatt, G.; Fletcher, J. C. Q.; Moss, J. R. Inorg. Chim. Acta 2007, 360, 2890.

9. Frisch, M. J. et al. Gaussian 03, Revision C.02, Gaussian Inc.:
Wallingford, CT, USA, 2004

10. (a) Fukui, K. J. Phys. Chem. 1970, 74, 4161. (b) Fukui, K. Acc. Chem. Res. 1981, 14, 363. 